\title{
Venezuela: presidencialismo, política de seguridad y el tránsito hacia la consolidación de un régimen híbrido
}

\author{
SANTIAGO JOSÉ CASTRO AGUDELO \\ Politécnico Grancolombiano \\ sjcastroa@poligran.edu.co
}

Docente de la Facultad de Ciencias Sociales del Politécnico Grancolombiano, integrante del Grupo de Investigación Derecho y Globalización, coordinador del Área de Constitución y Formación Ciudadana.

\section{Resumen}

Un régimen híbrido es aquel en el que se combinan la realización de elecciones periódicas para configurar el poder público con la existencia de déficit democráticos como la corrupción, la escasa o nula libertad de prensa, la inexistencia o debilidad de un sistema de frenos y contrapesos y, en algunos casos, la personalización del poder. En el presente ensayo se sostiene que en Venezuela la consolidación de un régimen híbrido se da gracias a la concentración del poder en la Presidencia de la República, que hoy ocupa Hugo Chávez, y a una política de seguridad y defensa que incluye la "politización de lo militar" y "la militarización de lo civil".

\section{Palabras Claves}

Régimen híbrido, presidencialismo, militarización, política de seguridad

\section{Abstract}

A hybrid regime is that which includes periodical elections that configure public power and democratic deficits like corruption, limits to freedom of press, the inexistence of a checks and balances system and, in some cases, the personalization of power. In this brief essay I suggest that in Venezuela the consolidation of such a regime is due to the concentration of power in the Presidency, today with Hugo Chavez in charge, and a security and defense policy that includes the "militarization of society" and the "politicization of the military".

\section{Key words}

Hybrid regime, presidentialism, militarization, security policy
Fecha de recepción: 23 de agosto de 2010

Fecha de aprobación: 4 de octubre de 2010

\section{Introducción}

Desde que el actual presidente venezolano, Hugo Chávez, asumió el poder, se ha iniciado un tránsito evidente hacia lo que $\mathrm{E}$ kman retoma como un régimen híbrido; es decir, hacia un modelo en el que el sistema político combina elecciones periódicas con un sinnúmero de déficit democráticos como la corrupción, libertad de prensa limitada, y un sistema débil de frenos y contrapesos entre el Ejecutivo y el Legislativo (Ekman, 2009). No obstante, al analizar dicho tránsito muchas veces se dejan de lado las características propias de un sistema presidencial y los riesgos que emanan del mismo hacia la concentración, e incluso, la personalización del poder público. De igual modo, si a ello agregamos la concepción política de la seguridad y la defensa, podemos evidenciar, al menos para el caso venezolano, que la "militarización de lo civil" y la "politización de la Fuerza Armada" (Jácome, 2009) parecen soportar la consolidación de dicho régimen.

Por tanto, en el presente ensayo se sostiene que la consolidación de un sistema presidencial fuerte, de la mano con una política de seguridad y defensa en la que se pretende una fusión entre la sociedad y la Fuerza 
Armada, son los pilares que sostienen y sostendrán el nuevo régimen híbrido que ha logrado asentarse en Venezuela.

\section{Presidencialismo y concentración del poder}

Giovanni Sartori define el sistema de gobierno presidencial como aquel en el que el presidente es elegido mediante una elección directa, por un periodo determinado, no puede ser desbancado por el parlamento, y designa y encabeza el gobierno sin que exista una autoridad intermedia (Sartori, 2005). Empero, Sartori también es enfático al afirmar que el modelo del sistema presidencial que se ha seguido en América Latina es aquel que se configuró en Estados Unidos de América en el siglo XIX, cuyo marco constitucional está diseñado para que un presidente no pueda gobernar, debido al complejo sistema de frenos y contrapesos que contempla. La única razón por la que dicho sistema funciona, insiste Sartori, es porque "lo hacen funcionar" (Sartori, 2005).

En América Latina está aún vigente el debate sobre los problemas del presidencialismo, pues los presidentes que no gozan de mayorías en el Legislativo muchas veces recurren a poderes reactivos, por ejemplo el veto u objeción ${ }^{1}$, para negar la legislación; o inclusive proactivos, como el mensaje de urgencia o inclusive la declaración del Estado de excepción ${ }^{2}$, en aras de forzar la posibilidad de gobernar por encima del control político que debe ejercer el órgano Legislativo.

1. El presidente se niega a sancionar los proyectos que han sido aprobados por el Legislativo.

2. El mensaje de urgencia usualmente obliga a que el Legislativo dé trámite a la legislación que impulsa el gobierno en un periodo reducido de tiempo, so pena de ser decretada por el gobierno. Al declarar el Estado de excepción el Ejecutivo puede proceder a legislar por decreto, es decir sus decisiones tienen fuerza de ley, al menos mientras se mantenga la excepción.
Tal es el caso del gobierno del presidente Hugo Chávez, más aún después del fallido golpe de 2002, en el que fue apartado del poder por casi 48 horas tras una masiva movilización ciudadana convocada por sectores de la oposición a su gobierno, después de la cual el entonces presidente de la Federación de Cámaras y Asociaciones de Comercio y Producción de Venezuela (Fedecámaras) asumió la Presidencia tomando juramente solo y ante un grupo de periodistas, contrariando claramente la Constitución Política de Venezuela.

Más adelante, tras un intento de boicot de las elecciones por parte de los sectores opositores en 2005, que optaron por no participar en las elecciones legislativas, las 167 curules de la Asamblea Nacional fueron ocupadas por el Movimiento Quinta República y otros partidos también pro Chávez (Ekman, 2009). Poco después, en 2007, al presidente le habían sido aprobadas facultades extraordinarias por un periodo de dieciocho meses (Ekman, 2009). Esto confirma, además, la existencia a partir de 2005 de lo que Mainwaring y Shugart (2002) denominaron en su momento poderes constitucionales y partidarios de un presidente, es decir la convergencia entre los amplios poderes reactivos y proactivos consagrados en la Constitución Política y el control de los partidos políticos que ocupaban una mayoría de escaños en la Asamblea Nacional de Venezuela.

Cabe recordar, no obstante, que la llegada al poder de Hugo Chávez en 1998 era probablemente la muestra más evidente de la decadencia del sistema bipartidista venezolano, conformado por el Partido Demócrata Cristiano (CopeI) y el Partido Acción Democrática (AD), que ya habían sufrido sendas derrotas en las elecciones legislativas y en 1999 tenían que declarar la libertad de sus militantes para votar en los referendos que convocarían primero a una Asamblea Nacional Constituyente, y luego ratificarían una nueva 
Constitución Política, ahora de la República Bolivariana de Venezuela, aprobada según los intereses del nuevo mandatario venezolano ese mismo año (Alcántara, 2003). Sin embargo, Chávez no lograría el control absoluto de la Asamblea sino hasta el año 2005.

A partir del control de la Asamblea Nacional, un amplio presupuesto para inversión, derivado de los recursos que recibe Venezuela por concepto de la exportación de petróleo, motor de su economía, y los programas sociales que viene fomentando el gobierno venezolano, muchos de carácter asistencialista y con claros objetivos políticos ${ }^{3}$, Chávez ha logrado consolidar una fuerza política propia que llevó a la creación en 2008 del Partido Socialista Unido de Venezuela (PSUv). Con este, en las elecciones regionales de 2008 logra el control de la mayoría de estados y municipios, a pesar de haber perdido el control de algunos con mayor relevancia como el estado de Miranda (ICG, 2009).

Logrado el control político de buena parte de las entidades territoriales y con el control de la Asamblea Nacional, Chávez decide insistir en dos elementos que le habían sido negados en un fallido referendo llevado a cabo en 2007 para modificar la Constitución $n^{4}$. la reelección indefinida y la aprobación de varios proyectos de reforma que, en últimas, lograban concentrar aún más funciones en el Ejecutivo nacional (ICG, 209). Mediante referendo, en 2009 se aprueba la reelección indefinida y pronto la Asamblea Nacional aprobaría un amplio paquete de reformas. La nueva legislación restaba autonomía a las autoridades locales y ello permitía que Chávez controlara los estados y

\footnotetext{
3 Ekman (2009), por ejemplo, sugiere que por medio de la introducción de programas de cobertura en salud y alfabetización, Chávez logró suficiente respaldo para ganar el referendo de agosto de 2004 que buscaba iniciar el proceso para la revocatoria de su mandato.

4 Recuerdo que Chávez desde el día en que se conocieron los resultados del referendo de 2007 calificó el triunfo de la oposición como una "mierda" y anuncio que no deberían estar celebrando.
}

municipios donde había perdido en las elecciones de 2008. Sin embargo, ese mismo año ya había sido promulgada la ley orgánica de la Fuerza Armada Nacional Bolivariana, nuevo componente de la política de seguridad y defensa del Estado venezolano, que también permitía la subordinación de autoridades locales con la activación de las regiones estratégicas de defensa integral, "espacios territoriales que serán administrados por mayores generales designados por el primer mandatario" (Jácome, 2009). La política de defensa y seguridad ya jugaba un papel central en el proyecto bolivariano.

\section{Militarización de la sociedad y politización de lo militar}

Una de las conclusiones clave del fallido golpe contra el presidente venezolano en 2002, fue la necesidad de mantener a como diera lugar el control sobre las fuerzas armadas, pues en últimas fueron estas la que cedieron a una aparente presión popular para pedirle que se retirara del poder, solo para tener que llevarlo de regreso al palacio de Miraflores horas después. La reacción internacional del momento no fue clara. De hecho el entonces presidente de Colombia, Andrés Pastrana Arango, no demoró en reconocer, al menos en los medios de comunicación, al gobierno de Pedro Carmona, quien se posesionó, como ya se anotó, ante las cámaras de televisión y no ante la Asamblea Nacional o las cortes. Tampoco se podía pedir más, pues Venezuela había logrado incorporar cláusulas defensoras de soberanía y de no intervención a la Carta Democrática de la oEA en septiembre de 2001 (Suárez y García, 2008).

Ya era evidente que Chávez debía contar con el respaldo de las Fuerzas Armadas si quería continuar en el poder, más aún de seguir con su empeño de impulsar amplias reformas en materia social, económica y política. Para ello, sin embargo, era menester lograr implantar una 
nueva organización político-militar al interior de las mismas. El modelo cubano no demoraría en aparecer y en el marco del ALBA (Acuerdo de cooperación e integración impulsado por Chávez desde 2001 y que incluye a Bolivia, Ecuador, Cuba y Nicaragua) es especialmente importante la relación con la isla, que incluye, según sostienen algunos analistas, "un mayor intercambio y cooperación militar" y el "acercamiento estratégico-militar a China, Rusia e Irán y a otros rivales de Estados Unidos y sus aliados" (Jácome, 2009). Es decir, Venezuela y sus Fuerzas Armadas hacen parte de ese bloque "contra-hegemónico", que ha desafiado la unilateralidad y la imposición de un modelo económico y político por parte de Estados Unidos.

Ese realineamiento no es solo hacia afuera sino claramente hacia adentro y en especial a partir de la aprobación de la Ley Orgánica de la Fuerza Armada Nacional Bolivariana, mediante decreto de julio de 2008 (Jácome, 2009). "Se mantiene el lema de Patria, socialismo o muerte $\cdots$ venceremos” (Jácome, 2009), y se incorpora a la Milicia Nacional Bolivariana como parte integral de la FANB, que depende exclusivamente del presidente de la República y debe "entrenar, preparar y organizar al pueblo para la defensa de la Nación” (Jácome, 2009). Esto último incluye la actuación en caso de perturbación del orden interno y lo más preocupante, para algunos, la Reserva y la Guardia Territorial están subordinadas a la Milicia. El hecho que esta se active en el "Plan República" durante los procesos electorales y que hoy por hoy el control civil de la FANB corresponda casi de manera exclusiva al presidente, llevan a afirmar que "lo que se ha producido es más bien una militarización de lo civil" (Jácome, 2009).

Los procesos de expropiación, cierre de medios de comunicación como la cadena RCTV en 2007, la represión de las protestas de grupos opositores, entre otros (ICG, 2009), no podrían llevarse a cabo sin la activa participación de la FANB o de su nuevo componente: la Milicia Nacional Bolivariana. La ley, el Estado de Derecho y la misma Constitución ¿dónde quedan si el lema claro es "patria, socialismo o muerte"? Y es que "bajo la Constitución de 1999 la sociedad tiene corresponsabilidad en la defensa y seguridad según el artículo 326" (Jácome, 2009). El problema es que, como se anotó, la seguridad y la defensa hoy por hoy dependen exclusivamente del presidente de la República.

\section{Consideraciones finales}

Con este breve recuento se buscaba evidenciar mejor cómo Venezuela hace el tránsito hacia un régimen híbrido, que sigue basando, mal que bien, su legitimidad en la realización periódica de elecciones; pero que por medio de la concentración del poder en la Presidencia, el control absoluto de la FANB por parte del presidente, y un activo papel de la Milicia Nacional Bolivariana en los procesos electorales, ha logrado aumentar los déficit democráticos.

En términos de Sartori (1994), podríamos decir, a la vez, que en Venezuela hay una democracia, en tanto se presentan elecciones para la configuración del poder político, pero con bajos grados de democraticidad, pues no hay ya separación de poderes, no hay libertad real de prensa y las elecciones se pueden cuestionar como poco libres y competitivas. Esto último puede ayudar a definir también los regímenes híbridos que ya se anotaron y eso es precisamente lo que parece estar ocurriendo en la Venezuela del socialismo del siglo XXI.

No obstante, cabe anotar que en las pasadas elecciones legislativas realizadas en septiembre de 2010, Hugo Chávez no lograba obtener las dos terceras partes del total de 167 diputados de la Asamblea Nacional, lo 
cual implica, al menos en teoría, una nueva relación de negociación y transacción con los sectores de la oposición. Si a esta se le permite abiertamente ejercer el control político al gobierno y debatir e incluso modificar las iniciativas del ejecutivo, Venezuela podría retomar el camino hacia un régimen democrático con un sistema presidencial y el correspondiente sistema de frenos y contrapesos; de lo contrario, es decir, si el gobierno sigue encontrando la manera de impulsar sus políticas, ahora por encima de la Asamblea Nacional, donde ya no tiene mayorías calificadas, habrá ahora más evidencia para soportar la existencia de un régimen híbrido, pues si bien se realizan elecciones, los déficit democráticos serán innegables.

\section{Bibliografía}

1. Álcantara, Manuel (2003). Sistemas politicos de América Latina. Madrid: Tecnos.

2. Ekman, Joakim (2009). Political Participation and Regime Stability: A Framework for Analyzing Hybrid Regimes. En International Political Science Review. 30 (1), January.

3. International Crisis Group (ICG). (2009). Venezuela: Accelerating the Bolivarian Revolution. Latin American Briefing (22), Bogota, November $5^{\text {th }}$.

4. Jácome, Francine (2009). La política de seguridad y defensa del gobierno de Venezuela en 2008. En Mathieu, Hans y Rodríguez, Paula. Anuario 2009 de la seguridad regional en América Latina y el Caribe. Bogotá: Fescol.

5. Mainwaring, Scott; Shugart, Mathew (2002). Presidencialismo y democracia en América Latina. Buenos Aires: Paidós.

6. Sartori, Giovanni (2005). Ingeniería constitucional comparada. México: Fondo de Cultura Económica.

7. Sartori, Giovanni (1994). ¿Qué es la democracia? Bogotá: Ediciones Altamir.

8. Suárez, Luis; García, Tania (2008). Las relaciones interamericanas: continuidades y cambios. Lección 8. Buenos Aires: Clacso. 